ISBN 978-93-84468-75-0

2016 International Conference on Business, Human Resources and Education

(ICBHRE-16)

Oct.11-12, 2016 at Dubai (UAE)

\title{
Musical style JAZZ, the new way of Leadership (Classical, Jazz, Evergreen Live piano interpretation)
}

\author{
Mihail Kitanovski \\ Kitanovski \& D2EM Consulting, ul. Nikola Parapunov 27, Skopje, Macedonia, \\ mkitanovski@d2emconsulting.com
}

\begin{abstract}
This document presents the new vocabulary for learning, discussing and implementing know how about leadership, team building and sales. Very important issues of today's business world are directly connected of key professional characteristics: loyalty, common sense, logic and knowledge power. Live piano performance and video records of classical, jazz and evergreen music performances are presented in order to illustrate the points and the presenter deliver a powerful and interactive keynote speech. The logic of advanced leadership cum through improved communication, collaboration, trust, listening, creativity, preparation and performance. This is one of the unique way to connect music creation with business challenges and how it helps to re-enforce important messages about teamwork and leadership
\end{abstract}

Keywords: leadership, empowering leaders, piano performance, jazz, music as metaphor

\section{Leadership}

A major function of leaders is to motivate other individuals and groups. (Note that leaders can also focus on motivating themselves when their focus is on self-leadership.) There are approaches to motivating people that are destructive, ego, fear, intimidation, etc. While these approaches can seem very effective in promptly motivating people, the approaches are hurtful, and in addition, they usually only motivate for the short-term. There are also approaches that are constructive, eg, effective delegation, coaching, etc. These approaches can be very effective in motivating others and for long periods of time.

\subsection{Motivating employees starts with motivating yourself}

As mentioned in real world, employees can be all fired up about their work and be working very hard. However, if the results of their work don't contribute to the goals of the organization, then the organization is not any better off than if the employees were sitting on their hands. Therefore, it's critical that managers and supervisors know what they want from their employees. These preferences should be worded in terms of goals for the organization. Identifying the goals for the organization is usually done during strategic planning. Whatever steps you take to support the motivation of your employees (various steps are suggested below), ensure that employees have strong input to identifying their goals and that these goals are aligned with goals of the organization. (Goals should be worded to be "SMARTER"). It's amazing how, if you hate your job, it seems like everyone else does, too. If you are very stressed out, it seems like everyone else is, too. Enthusiasm is contagious. If you're enthusiastic about your job, it's much easier for others to be, too. Also, if you're doing a good job of taking care of yourself and your own job, you'll have much clearer perspective on how others are doing in theirs. A great place to start learning about motivation is to start understanding your own motivations. The key to helping to motivate your employees is to understand what motivates them. Don't just count on cultivating strong interpersonal relationships with employees to help motivate them. The nature of these 
relationships can change greatly, for example, during times of stress. Instead, use reliable and comprehensive systems in the workplace to help motivate employees. For example, establish compensation systems, employee performance systems, organizational policies and procedures, etc., to support employee motivation. Also, establishing various systems and structures helps ensure clear understanding and equitable treatment of employees.

\section{Jazz - music style}

Creative people and their processes play a prominent role in business processes as organizations seek to deploy the merits of business process management to more than just the set of transactional processes. Product development and marketing campaigns are just two examples of such creativity-intensive processes that increasingly find their way into the agenda of process managers. Besides this, there are entire and quickly growing industries designed around creative processes, with the entertainment industry being the most prominent example of a creative industry.

Much of what happens in jazz is strongly influenced by the rather rigid structure of the genre. But, far from being an obstacle, the structure provides a set of agreed-upon "rules of the game" that allow musicians to come together and play jazz with little more advance communication than is required to pick a tune and the key to play it in. Understanding this structure is essential to playing jazz well.

The structure of jazz has three principal components: rhythmic, formal, and harmonic. The rhythmic component dictates fixed rhythmic relationships among the participating instruments. The formal component is based largely on popular song forms, which follow a few small, highly predictable patterns. The harmonic component is governed by a relatively small number of types of chord progressions; however, these chord progressions - and the individual chords themselves - are subject to a great deal of variation and elaboration, which accounts for much of the real complexity encountered in jazz. Accordingly, several sections of this book will be devoted to various aspects of jazz harmony. Rhythm and form will be treated in this section.

The rhythmic, harmonic, and formal components together confine jazz to a fairly narrow range of musical possibilities. Jazz has been criticized for these limitations1, but it is this very confinement that allows several musicians to collaborate successfully in the production of mostly improvised performances

The dynamic musical world of jazz provides an excellent illustration of this new corporate environment. The session begins with a short performance, giving participants an opportunity to listen and observe how jazz musicians improvise and innovate within clearly defined structures, make changes, be more flexible, take risks, value diversity, rotate leadership and build on each other's ideas in performance. The live performance by the conductor [2]. A critical lesson for new managers and supervisors is to learn to focus on employee behaviors, not on employee personalities. Performance in the workplace should be based on behaviors toward goals, not on popularity of employees. You can get in a great deal of trouble (legally, morally and interpersonally) for focusing only on how you feel about your employees rather than on what you're seeing with your eyeballs. A Jazz interpreter is $100 \%$ focused on the team and about their reactions. If there is a need for making additional improvisations to help the colleague, there is no doubt about the creation of new music rhetoric's during the music performance. The great leader should do and follow the same approach.

\section{Other methodologies and experiences - music orientation}

\subsection{Classical}

In order to present the main characteristics, the conductor first present video/sound presentation of classic music [1]. Then the session continues with presentation of the highlighting notes about how the team members (the team that plays classical music) are balancing listening and responding, emotional awareness, preparation, self-discipline, concentration, rationality and emotional flow, as well as personal and shared responsibility in performance. By live piano performance, Mihail Kitanovski present the ability of new Leaders and/or Salesman, how these characteristics should be implemented in real business world and communication processes. 


\subsection{Evergreen}

The performance of evergreen orchestra is one the most effective and powerful metaphors. Knowing the overall strategy helps the company's workforce stay focused on the organizational mission: meeting the needs of the consumers in that target market. Even if the company implements smart policies, competitors might steal customers, unexpected disasters might cripple operations and economy fluctuations might erode the buying capabilities of target market. Corporate policies are only as effective as their implementation. Good corporate governance requires having the discipline and commitment to implement policies, resolutions and strategies. Fairness must always be a high priority for management. Companies also must be fair to their customers, both for ethical and public-relations reasons. Managers sometimes keep their own counsel, limiting the information that filters down to employees. When employees understand management's strategies and are allowed to monitor the company's financial performance, they understand their roles within the company. Using a live piano performance by conductor and video presentation [3], participants are invited to engage in an interactive discussion how playing in an orchestra mirrors working in a large organization.

The keynotes are trust, listening, collaboration, preparation and technical excellence. Participants also learn how the conductor (without music and speech) provides leadership and team leading during the performance.

\subsection{Live piano performance}

The presenter/conductor begins by performing selected pieces of piano music to try to present how highlevel musicians master technique, concentration and emotional power could be performed by combo/mix of Classical, Jazz, Evergreen music, 7/8 and 9/8 rhythm and self-composing music - A minor. The participants are invited for questions and discussions about the form of their own experience, especially that gained in a particular profession at work.

Participants learn how the metaphor of music provides a new way of leadership, teamwork and salesman through to be competent in all aspects of work, including management, professional knowledge and skills up to date, by regularly take part in activities that maintain and develop competence and performance, to be familiar with guidelines and developments that affect the work and to take steps to monitor and improve the quality of personality.

\section{Outcome and expectations}

- Intensive time of self-discovery and expanding leadership and sales mindset and skills

- Inspiring our leaders and salesman to stretch to their fullest potential

- Elevating the sense of purpose and a shared responsibility for the work and for the team

- Using knowledge as a power and using soft skills to reach common success and business logic

- Elegant performance and creative thinking

- Creative music and business adventures

- The piano follows the audience requests concerning sales, leadership and management power

- Admirable, moving and educational experience

\section{Implementing sessions and time management}

During the interactive sessions, the management quality system should be presented in order to put in place the key management points. First and second level managers are going to follow and discuss the criteria for key performance indicators and the system of quality control, quality assurance and continual measurement as a key part of managing organizations. Training sessions are also emotional and result oriented. The following sections are explained by the content and audience feedback. 


\subsection{The management training session 1 st Part}

- How to improve leadership performance.

- KPI, Targets and Risk.

- Connect key business principles like trust, respect and execution.

- Exploring the parallels between music and business.

\subsection{Music - live piano 2nd Part}

- By performing selected pieces of piano music in order to illustrate high-level musicians master technique, concentration and artistry.

- Personal development and inviting participants to embrace new ways of thinking about business practice.

- Manager's type presentation

\subsection{Audience session 3rd Part}

- Using a series of carefully crafted exercises, by an interactive discussion about creativity,

- self-development and social interaction in the workplace.

- How both musicians and business leaders need to embrace new challenges and reinvent themselves in the face of change.

\section{Conclusions}

Management and music as metaphor is the practice of helping organizations improve their performance through the analysis of existing problems and executing development plans. It is increasingly engaged by various companies in consulting assignments which address a very wide range of problems, challenges and opportunities. There are many variety of leading edge methodology, which includes the management process (Diagnose, Design, Develop, Deliver, Demonstrate Results) and when dealing with change management challenges, one of the ways for implementing such a methodology and implementation management workshops. Ultimately it is very important to bring a world-class range of diagnostic tools and assessments to apply to the analysis and development of great business solutions. D2EM works with clients to help identify issues and solve problems using a systematic and creative approach, with the nature of the situation and the particular request of the client. In particular, the assignment may range from ad hoc advice on a particular problem or issue, to the design of comprehensive systems for the client as well as the evaluation and revision of existing systems.

\section{References}

[1] Sonata in C major, 1st movement, K545, W.A. Mozart

[2] Summer Time, George Gershwin G Minor, video presentation of Manhattan Jazz Orchestra 2012

[3] Toccata J.S. Bach - D minor, 2013 